\title{
Learning the 'Tracker' process: a case study into popular music pedagogy
}

Brendan Anthony has an international career as a popular music producer (30 years) and lectures in music production within the Bachelor of Music at the Queensland Conservatorium, Griffith University. Brendan's research engages with popular music production, popular music education, and the relationship between technology and music production creative practice.

Contact: Queensland Conservatorium of Music, Griffith University, South Bank Campus, 140 Grey St, South Brisbane QLD 410, Australia.

E-mail: b.anthony@griffith.edu.au

Paul Thompson is a recording engineer and Reader at Leeds Beckett University in the School of the Arts. Paul's research engages with record production, audio education, popular music learning practices, creativity and cultural production in popular music. His book 'Creativity in the Recording Studio: Alternative Takes' was published in 2019.

Contact: Leeds Beckett University, Caedmon 221, Headingley Campus,

Leeds, LS6 3QS

Email: p.a.thompson@1eedsbeckett.ac.uk

Tuomas Auvinen is a Finnish musicologist, songwriter, producer and musician. $\mathrm{He}$ completed his $\mathrm{PhD}$ in musicology in 2019. Tuomas works as an educator in music production and ethnographic methodology at the University of Turku and is a board member and editor for the Finnish Society for Ethnomusicology.

Contact: tuomas.a.auvinen@utu.fi

Phone: +358407380860

Key words: Popular music pedagogy, record production, Tracker producer, Top-line songwriting, online music production, popular music production. 

Abstract
The 'tracker' production process is a modern form of music production agency where top-line songwriters work with music programmers called 'trackers' primarily within the confines of the DAW. In this case, production, songwriting and performance often happen concurrently and collaboration involves the synthesis of ideas, musical negotiations and expertise in using digital and online technologies.
In providing popular music production learning activities that translate to professional contexts, higher education institutions face a number of challenges particularly where much of the collaboration is undertaken online. This article reports on a cohort of Bachelor of Popular Music students who undertook a tracker process module. Students' perceptions of 'engagement' and 'learning' were captured via an assessment item and survey and a themed analysis indicated the pedagogy promoted the use of diverse social skills, was highly collaborative, relied both on specialist and non-specialist knowledge and involved the use of digital and online communications. 


\section{Introduction}

The role of the record producer in commercial record production has developed over time in response to economic, musical and technological changes (Zak 2001; Moorefield, 2005). Before the mid-1960s, the producer was expected to be a 'fixer (booking artists, musicians, and studios), plus the ultimate manager of time and resources' (Hepworth-Sawyer and Golding 2010: 3). Howlett (2009) proclaims that the producer's role is as an intermediary that operates within the social context of music making working with artists, engineers and record companies. More recently, production landscapes have expanded beyond the recording studio and the producer may also be expected to contribute to the songwriting, arranging, engineering or performance on a recording (Thompson, 2019). The tasks involved in producing therefore depend upon the demands of the musical context because 'different genres and subgenres of recorded music have their own production requirements' (Burgess 2014: 7).

Popular music recordings involve the contribution of various music production tasks and the culmination of these, and the agency they afford the record producer, help to shape the musical output (Anthony and Lefford, 2019). In Rock music for example, the main production tasks are 'songwriting, arranging, performing, engineering and producing' (Zak, 2001: 164) and separate individuals or groups of individuals would undertake each of these specific tasks. The development and adoption of digital music production tools, shrinking recording budgets, and the ubiquitous use of the Internet, has led to a more fluid integration of roles and responsibilities (HepworthSawyer and Golding, 2010; Théberge, 2012). In Pop music production (Top-40 for example) tasks may also include music programming, where the musical arrangement and instrumentation can be built within the Digital Audio Workstation (DAW) and top-line writing - melody and lyrics (Thompson and Harding, 2018). Moorefield (2005) describes these more recent music making landscapes as the 'producer genres' because in these situations the music production tasks may be performed by a single person; the producer. The production process of popular music genres such as hip-hop and electronic dance music (EDM) too involve a particular focus on the use of digital tools within songwriting and arranging and Seabrook notes that:

By the mid-2000s the track-and-hook approach to songwriting - in which a track maker/producer, who is responsible for the beats, the chord progression, and the instrumentation, collaborates with a hook writer/top-liner, who writes the melodies - had become the standard method by which popular songs are 
written. (2005: 200)

Seabrook (2015) further notes that 'tracking' (as described above) encompasses the acts of making backing tracks within the DAW and developing these into songs with the addition of a top-line melody (see also Auvinen, 2017). This music production process therefore differs from the more traditional practice of writing a song and then recording the instrumental parts in a recording studio prior to mixing (Zak, 2001). The tracker process also removes some of the logistic issues associated with traditional music production; the DAW and the Internet affords the producer/artist the ability to share musical ideas, audio files or complete sessions without the need to be in the same room. Consequently, popular musicians and music producers have developed ways of working virtually and remotely within 'online' studio environments.

The 'tracker producer' (Auvinen 2016; Hiltunen 2016) can be classified as a type of bedroom producer (Hepworth-Sawyer and Golding, 2010) that utilizes professionallevel yet affordable digital music production tools such as the DAW, and the virtual music collaborative environments that the Internet provides. However, this adaption to songwriting and music production agency shapes the form of the musical output (Koszolko, 2017) and so the producer requires foresight to understand how this style of creative practice can be used to meet the artist's intentions and the expectations of the listening audience (Anthony and Lefford, 2019). Learning the tracker process therefore, is increasingly relevant to both students and providers of Popular Music Education (PME). So much so that Bennett posits 'it is difficult to argue that a hypothetical popular music curriculum that eschews digital music production skills is not hindering its students' creative development' (2017: 291).

This study focuses on the delivery of a tracker process educational module that forms part of a Bachelor of Popular Music Program (BPM) at an Australian University. In this study we illuminate students' perceptions of learning and unpack their experiences of the creative practice that is associated with the tracker process. This module places students in a 'profession-based' popular music production setting in which tracker producers are required to work with top-line writers primarily through online collaboration. Students studying the module were asked to evaluate their experiences of learning the tracker process and how online collaboration impacted their ways of working, their decision making, and the overall aesthetic results. Therefore, we use student reflections from a questionnaire and the students' written assessment item (creative synthesis) to form the basis of data 
collection. This particular case concludes by highlighting some potential issues, strategies and useful pedagogical considerations for embedding the tracker process within a popular music educational context. To setup the case study, we first table a review of the literature surrounding popular music education (PME) and a discussion of the 'key skills' of the tracker process.

\section{Context}

Traditionally, Popular Music Education (PME) has been delivered across various disciplines and departments such as music, sociology and cultural studies. However, Théberge (2000) suggests that: "popular music can be experienced as a form of "practice", not simply as an "object” to be studied' (Théberge, 2000: 35; See also Small, 1998) but contemporary PME curricula have struggled to incorporate and develop this element of practice and an acknowledgement of how popular musicians typically learn (Thompson, 2012). Lebler $(2007,2008)$ showed that popular musicians learn via self-assessment, peer feedback and self-directed learning. Lucy Green's work $(2002,2006)$ supported these findings and showed further how informal popular music learning practices such as listening and copying, jamming, playing, singing, improvising and composing often take place informally and can take place in formal contexts with minimal supervision. Popular musicians' learning therefore relates more closely to Macedo's (2013) phenemenological work, Lave and Wenger's (1991) situated learning and Kolb's (1984) experiential learning in which providing frameworks for more socialized learning can also help to create a sense of accomplishment by the student when producing content (Waldron, 2016; Waldron et al., 2018). Consqeuently, popular music students require the ability not only to critique themselves but also to be comfortable within 'peer learning' frameworks (Lebler, 2008).

Formal education however has been slow to create frameworks that encourage learning practices that typically take place informally. In addition, they only tend to focus on one element of what is often a multi-faceted process. For example, studio recording pedagogy in Higher Education (HE) has:

Often focused on the technical aspects of studio practice at the expense of the social, aesthetic and human skills required by the industry. These formal frameworks often only focus on the transference of knowledge to the individual diminishing or ignoring the important processes of interaction with the participants in the field. (Davis, Parker and Thompson, 2014: 1) 
Within formal education there is typically a focus on learning the knowledge system of a particular area called the domain with a reduced emphasis on learning the mechanisms that govern the selection of creative work. For example, in order to learn to be a songwriter McIntyre (2007) showed that the development of knowledge, or in his terms domain acquisition, was an essential but not sufficient part of a practitioner's ability to be a successful songwriter. A student's opportunity to engage with the social organisation that understands, uses and alters the knowledge system that they are attempting to learn is therefore a critical aspect of becoming a creative practitioner. Csikszentmihalyi further explains:

a person who wants to make a creative contribution not only must work within a creative system but must also reproduce that system within his or her mind. In other words, the person must learn the rules and the content of the domain, as well as the criteria of selection, the preferences of the field. (1997: 47)

In his study of songwriting pedagogy, Joe Bennett further concluded that the:

Curriculum, then, must engender four things: increased domain immersion, an ability to be self-critical and edit work, genre-agnostic creative freedom, and the building of an improved portfolio of work. (2015: 47)

In order to allow students to become immersed in their domain and learn the rules that govern the selection of creative work, the environment and context in which learning takes place becomes increasingly important (Anthony, 2015; 2018). Here, formal education can acknowledge current 'cultures of music making' (Folkestad, 2006: 144) and gravitate musical tasks towards a 'profession-based' experience that can be contextualized within the classroom (King, 2016). Importantly though, within the profession of popular music production, the process has moved beyond the physical limitations of the recording studio and the classroom. This is because music producers now routinely collaborate with musicians, artists and songwriters via remote and online means extending the musical and cultural knowledge needed to produce contemporary music.

The affordances that the Internet and online environments provide to music production education have been highlighted by Voss (2018) where various skills and techniques can be learned in practice-based scenarios. Draper (2007) explored the ways in which social media and social networking through the Internet have changed the ontology of music creation and music pedagogy. Draper found that a diverse 
range of online initiatives promoted the idea of a music 'learning ecology' (Draper, 2007: 1) where student collaboration and peer review encouraged students to 'do the driving' and take ownership for their own learning (Draper, 2007: 1). These studies attest to the ways in which the Internet can provide new modes of learning, however because the tracker process is a relatively recent development within the cultures of music-making, it has only recently begun to be acknowledged in the scholarly literature.

The tracker is a type of music producer (Seabrook, 2015; Auvinen 2016; 2017 and Hiltunen 2016) and their central role is to:

'come up with the 'tracks' for a song, which would translate into the arrangement in traditional songwriting terms. In spite of the arrangement being his main responsibility, the traditional technical copyright-related term 'arranger' would not be sufficient to describe [it] (Auvinen 2017, para $50)$.

Other duties might include selecting sounds, recording, editing and giving feedback on the vocals; responsibilities that traditionally belong to the engineer and the artistic/creative producer. The role of the 'tracker' is interrelated with digital technological practices, which creates an ambiguous distinction between production and composition because of the: 'increasingly important role of technology in the process of music making' [Hiltunen, translation from the original Finnish by Tuomas Auvinen] (2016: 6). Auvinen (2017) further adds that:

the term programmer as an attribute of the producer's agency comes up in interviews and conversations much more often than the more traditional term musician. The constant renegotiations, overlaps, blurred lines, and switches between the different agencies might reflect a flexible production culture, in which anyone can do anything depending on the situation. (Para 54)

Programming, which refers to the task of producing and arranging sounds from within a computer using a DAW or external device, is a core skill of the 'tracker'. Programming in this sense becomes a form of songwriting or arranging, and the creative practice of the tracker becomes even more democratized and delocalized by the ways in which the tracker operates outside of the recording studio or a traditional music production context. Trackers are now capable of 'remote' collaboration (Bennett, 2018), where musicians sync DAW software to Internet storage mediums such as Dropbox and sessions are updated seamlessly to all participants' hard drives. The tracker producer can operate in musical styles where the majority of music 
making is done within the DAW, such as pop, hip-hop, or more broadly 'urban pop' (Auvinen 2016, 2017; Burgess, 2008). This newly defined role of the 'tracker' then is simply a continuation of the developing typologies of the producer as the economic, social, musical and technical expectations of contemporary popular music continue to change.

Here, what we call the tracker process is a term that incorporates the combination of the top-liner and the tracker working together (Hiltunen 2016: 6). Although this is similar to Bennett's (2011) 'top-line model' of songwriting, the tracker process goes beyond the act of simply writing a top-line and an accompaniment; it becomes the actual production of a musical event that is manifested in a sound recording. The top-liner and the tracker are often equal partners and an 'even split' distribution of songwriting credits between the tracker and the top-liner is common (Auvinen 2016: 21).

Although there is only one other study in this area (Bell, 2019), the survey of PME literature provides a useful framework for highlighting the considerations for teaching the tracker process. The context needs to create the opportunity for students to learn the domain and the criteria of the field, allow for 'peer learning' frameworks (Lebler, 2008) and place students in a close to 'professional' situation that can be facilitated rather than governed by the educator. Here, the educator responds 'to his/her students' needs, regulates control levels and differentiates instruction by giving and removing assistance' (Cremata, 2017: 76). In this scenario the educator acts as a representative of the field, offering feedback but also facilitating the process, which helps to promote a pedagogical environment where the student is responsible for the development of their own learning and may allow informal learning to take place. The literature also provides a basis for the term 'tracker' which has been broadly defined through the notion that technology, such as the DAW, is central to their role in creating musical material. For the purposes of this study, the tracker process has also been further defined as a form of contemporary music-making that involves a combination of creating the backing track and the topline melody.

\section{'The tracker process': key skills and competencies}

There is no 'absolute' model of what a tracker is expected to do but a tracker's key skills and competencies can be broadly grouped into three main areas; much the same as any record producer with musical, technical, socio-cultural knowledge (Thompson, 2019). Fundamentally, trackers need to be either songwriters, music producers or music programmers (Auvinen, 2017) and have some understanding of 
at least one or all of these skills. Throughout the process, these skills become fluid, overlap and interrelate and the tracker needs to be able to adapt to the artistic, sonic and or song-based requirements of the production. Musicians engaging in this process need to program a backing track and compose lyrics and a top-line melody, yet the exact process and order these steps are completed is often varied. The idea of sensemaking (Quintana et al., 2006: 128) is relevant whilst exploring the fluidity of the roles and skills in the tracker process. Sensemaking here means engaging in the basic practices of an activity, getting to know the different types of reasoning necessary to engage in a practice and understanding the terminology involved in a practice or activity. In a collaborative effort, such as making music in a tracker process, it is helpful that all participants have at least some knowledge about the different activities necessary to fully carry out the process. For example, a top-liner could get acquainted with the processes of programming tracks and recording vocals and a programmer could learn the basics of writing lyrics. This can be achieved through sensemaking, which can be seen as a prerequisite for the fluidity of the roles of a tracker process.

It is not essential that all participants are technologically minded for the tracker process to work but it is essential that one member of the tracker team is versed in the use of some form of DAW software. This includes aptitude in the many music sequencing applications for rhythm, bass and synthesizer instrumentation. Subsequently knowledge of synthesis and software-based audio engineering and mixing approaches that are discussed in texts similar to Graham (1979); Strange (1972); Hugill (2012); Moylan (2002) and Senior (2011) are desirable.

Trackers require a keen awareness of musicality with specific reference to instrumentation and vocal performance particularly as songwriting, production, performance and programming can all happen at the same time. The top-line participant should have suitable knowledge and ability in lyric writing, melodic design and vocal performance so as to write a 'top-line' that engages musically with the backing track and in turn manifests an emotional response from the listener (Howlett, 2007). The tracker must also understand the intricacies of how different singers' voices (pitch, timbre) can best be supported by suitable instrumentation; be it computer generated or acoustic-based (Anthony, 2015; Howlett, 2009).

Participants in the tracker process often engage in remote collaborations via the Internet (Bennett, 2018; Koszolko, 2017) and these can be combined with face-toface writing or recording sessions. Therefore, the participants of the tracker process need a firm grasp of cloud-based storage mediums, and an ability to work 
collaboratively within a group environment or on their own. For example, trackers and top-line writers often need to work on their ideas in private before presenting them to the rest of the team. The social interactions and communication practices that are continually at play within the tracker process are mediated by face-to-face or remote means within the various 'environments' that the production team works within. As such, all participants of the tracker process need to be comfortable in putting their ideas across and receiving critique of their work in varying communicative landscapes.

Importantly, this study responds to the call for the music curriculum to scrutinize the form that popular music production pedagogy takes. In addition to this, the design of the tracker producer module brings two further crucial elements into a contemporary and relevant music curriculum. Firstly, it introduces students to the mechanisms of selection that operate within the field of music production. Acquiring domain knowledge is a fundamental part of creative activity (Thompson and McIntyre, 2013) but students also need to learn: 'the criteria of selection, the preferences of the field' (Csikszentmihalyi,1996: 47). Learning the tracker process with guidance and feedback from an experienced member of the field crucially introduces students to these field expectations and preferences, and the criteria for selection that operates within it. Secondly, in order to be creative Thompson and McIntyre argue that a student: 'must dynamically interact with the field as it occurs in the professional world' (2013: online). So, by placing students in a profession-based contemporary scenario, it allows them to become socialized into the field of music production in which they can learn contemporary workflow methods of songwriting and production through a dynamic, multi-platform process.

\section{Study design}

Cohen, Manion, and Morrison suggest ' $[t]$ he central endeavour in the context of the interpretive paradigm is to understand the subjective world of human experience' (2000: 22) and so the following methodological approach has been designed to accommodate these perspectives. Principally, a mixed methods data collection approach was used to investigate teaching the tracker process. Data collection method 1 involved participants of the study completing an online survey following their completion of the course Music Production 2, via a Google Doc containing both closed (Likert scale) questions (Creswell, 2005) and open questions. The open questions allowed participants the opportunity to fully voice more personalized opinions of the tracker process and the learning experience. A copy of the online survey questions is available in Appendix A. For data collection method 2 
participants of the study gave their ethical consent for their assessment items (creative synthesis and the song audio) to be used for analysis.

A frequency analysis was applied to the Likert scale questions from the online survey and associated graphs were developed to represent responses. A thematic analysis (Bryman, 2008) was used by the research team for the open questions from the online survey, and the students' creative synthesis. Subsequently, various themes were identified and discussed to formulate findings. Ethical clearance was governed via the Griffith University protocol and as a result, informed consent was sought from all participants. The educator marked all assessment items prior to the data collection and analysis and therefore, the research ensured a suitably equitable experience for all students of the music production 2 module. Students' reflections via the assessment item (creative synthesis) and survey responses allowed the research team to critique student perspectives and hypothesize learning outcomes. By using a mixed methods approach, we hoped the triangulation of themes would become more visible during the analysis of the data collection methods outlined below.

\section{Facilitating The 'Tracker Process'}

The tracker process module makes up part of a $3^{\text {rd }}$ year course Music Production 2, within a Bachelor of Popular Music Program (BPM) in a university in Australia. In Music Production 2 students engaged with the tracker process as course work and as an assessment item from July 2018-October 2018.

\section{Tracker Module design underpinnings}

There were two central learning objectives guiding the module design. Firstly, the module sought to present students with an opportunity to diversify their 'practice' and 'skills'. The tracker process requires a different set of skills from that of acoustic instrument-based productions because it promotes the generation of electronic music production outputs, favours the application of computer-based technology (software, the DAW), utilizes different approaches to communication and collaboration (online/remote), which consequently impacts the structure and form of the musical output (Bennett, 2018). It was therefore intended by the module designer (one of the researchers) that participants would develop skills in areas they don't normally use; programmers may offer advice on lyrics and singers may engage with programming. Or participants may apply skills in different ways; performers may be working in genres that are foreign to them and online and remote communication and 
collaboration is a unique experience outside of interacting on social media. As such, by working through the module students had an opportunity to increase their skillset and promote their multi-disciplinary employment options for the future (Lebler and Weston, 2015).

Secondly, student learning was targeted as a journey of self reflection. Students were encouraged to document their process throughout, to explore the creative conflicts they experienced, what they found easy and some of the challenges they faced. Within the module assessment students were asked to consider and critique their process whilst also unpacking a reflection of one's self. Often these types of selfreflective assessments are limited to discussions of a musical output but by unpacking the social, cultural and musical realities of the tracker process, students were encouraged to identify elements where they can improve as music professionals. As a result, the tracker module was designed as a self-reflective music-making journey that engages students with the diverse realities of modern music production that will be experienced upon graduation.

Student collaboration was facilitated via face-to-face and online/remote means (inside and outside the classroom). Whilst collaborating online students were encouraged to utilize virtual communication platforms like Facebook chat and Skype for example. This type of pedagogical design bridges higher education models to that of industry practice where musicians communicate and collaborate virtually. This project facilitated student participation in face-to-face and remote/online composition, production and communication during the manifestation of an original popular music production that was generated primarily within the DAW. Students undertook lectures (where the tracker process was outlined to them) and tutorials (where they engaged in creative meetings and peer feedback sessions) and autonomous remote collaborative production sessions during which the music was composed and produced outside the classroom. The entire process was facilitated over a nine-week period, the pedagogical timeframe and assessment item descriptors are listed in Tables 1 and 2. 


\begin{tabular}{|c|c|c|}
\hline Week & Class type & Student activities and engagement \\
\hline 1 & Lecture & $\begin{array}{l}\text { The 'tracker producer and top-liner' production model is } \\
\text { explained to students. Students are advised that the majority of } \\
\text { their practical collaboration is to be via remote and online } \\
\text { means and the song is to be primarily composed and produced } \\
\text { inside the DAW. Students are advised to keep a reflective } \\
\text { journal which will inform the 'creative synthesis' assessment } \\
\text { item. }\end{array}$ \\
\hline 1 & Tutorial & $\begin{array}{l}\text { Students are separated into groups of 2-3 and are placed in } \\
\text { private musical spaces where they hold an initial face to face } \\
\text { creative meeting regarding the song they will be composing } \\
\text { and producing. }\end{array}$ \\
\hline 2 and 3 & $\begin{array}{l}\text { Autonomous work } \\
\text { outside the } \\
\text { classroom }\end{array}$ & $\begin{array}{l}\text { Over these two weeks, students engage in remote and online } \\
\text { collaboration of the tracker process from their home facilities } \\
\text { or similar. Students are encouraged to use social media 'chat } \\
\text { rooms' and storage points like 'Dropbox' to communicate and } \\
\text { transfer files and ideas. }\end{array}$ \\
\hline 4 & Tutorial & $\begin{array}{l}\text { Peer feedback class. Each group is required to bring their work } \\
\text { in (no matter what stage it is at), present it to the class and } \\
\text { receive feedback from class members. }\end{array}$ \\
\hline 5 & $\begin{array}{l}\text { Autonomous work } \\
\text { outside the } \\
\text { classroom }\end{array}$ & $\begin{array}{l}\text { Students continue their work outside the classroom and are } \\
\text { encouraged to take on board some of the feedback they have } \\
\text { received. }\end{array}$ \\
\hline 6 & Tutorial & $\begin{array}{l}\text { Students that need assistance with topline melody and lyrics } \\
\text { bring their song in for group work. The class spends a tutorial } \\
\text { improvising and collaborating with vocal composition on the } \\
\text { selected song/songs. }\end{array}$ \\
\hline 7 and 8 & $\begin{array}{l}\text { Autonomous work } \\
\text { outside the } \\
\text { classroom }\end{array}$ & $\begin{array}{l}\text { Students complete their tracker production and their creative } \\
\text { synthesis assessment item. }\end{array}$ \\
\hline Week 9 & NA & $\begin{array}{l}\text { Students submit their music and creative synthesis assessment } \\
\text { items. }\end{array}$ \\
\hline
\end{tabular}

Table 1: Pedagogical time frame

\begin{tabular}{|l|l|}
\hline Assessment item & Description \\
\hline Creative Synthesis & $\begin{array}{l}\text { A written personal reflection on the creative process and engagement with } \\
\text { the tracker production. The creative synthesis is a very good way to help } \\
\text { students unpack their musical process, what worked for them, what didn't } \\
\text { and why, and as such help develop their learning. }\end{array}$ \\
\hline Song audio & $\begin{array}{l}\text { The song is not marked in any way. It is used by the educator to better } \\
\text { understand various assertions made within the students creative synthesis } \\
\text { write up. }\end{array}$ \\
\hline
\end{tabular}

Table 2: Tracker process assessment items

All lectures and tutorials occurred in a university building comprising of lecture theatre/ computer lab, recording studio control rooms and recording rooms post/programming rooms. These can be seen in figure 1 .

Figure 1: QCM Lecture room/computer lab, control room, post room/programming room, recording room 

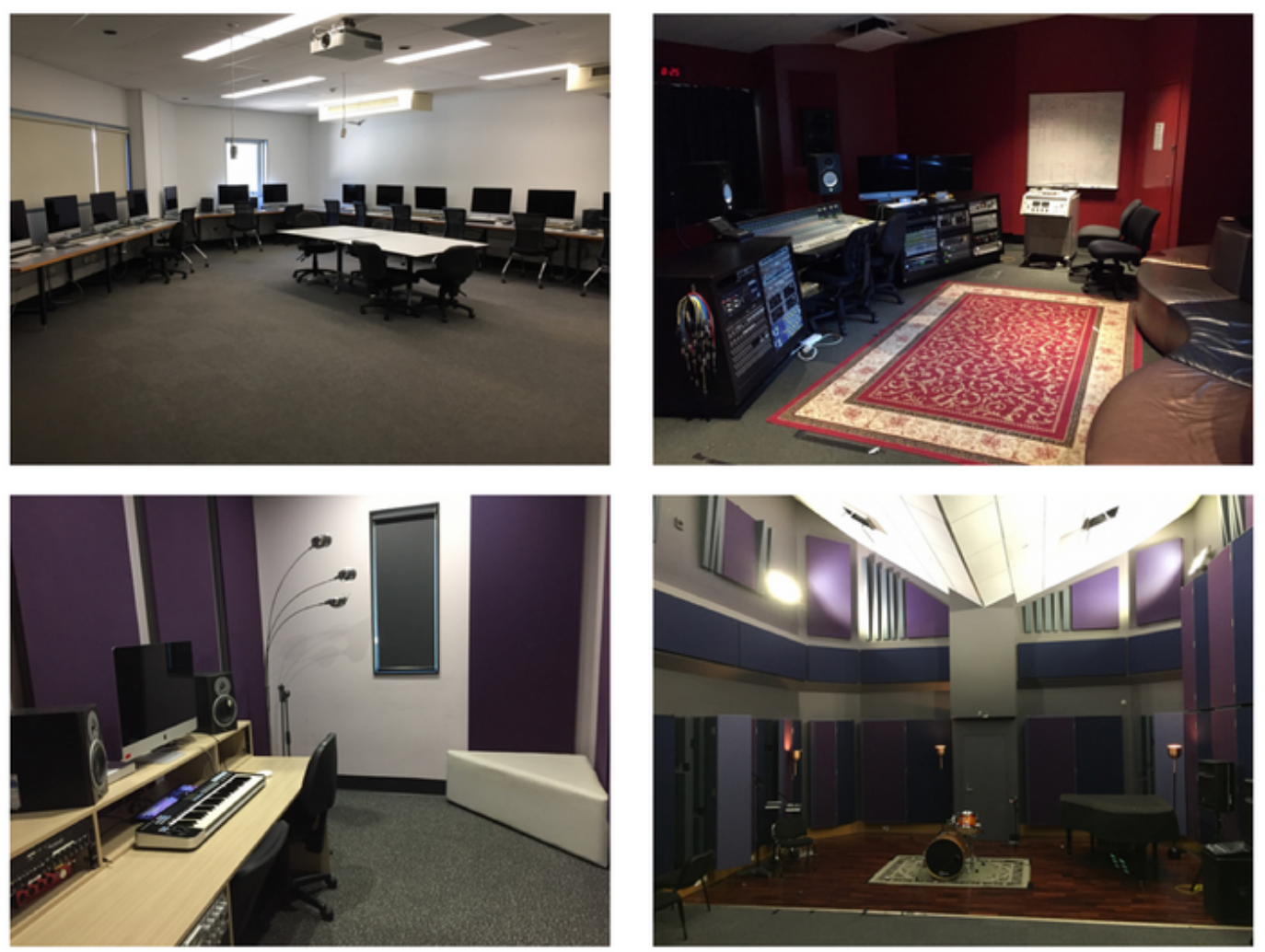

\section{Data analysis and Findings}

The demographic questions at the beginning of the questionnaire helped to provide some context to the students, firstly, the majority of the students were between the age 17-21 and a quarter were a little older (22-30). Secondly, the students undertaking this task were a diverse collection of popular musicians and categorized themselves as either a songwriter, producer, programmer (sequencer), musician (singer) or a combination of these. Despite all having received two prior years' instruction in songwriting, sound recording and music production, only a quarter of students considered themselves 'programmers'. However, when asked at the end of the module, more than half of the students stated that the skills they engaged in most as part of the tracker assessment was programming. This suggests that the tracker project encouraged students to engage with programming even if it was outside of their skillset and encouraged students to develop their programming skills.

The qualitative reflections submitted by the students within their written assessment allowed the study to delve deeper into the development of the students' knowledge and skills in some detail. Because the student reflections were based upon their processes, similar themes were documented and as a result common modes of learning practice, musical/technical development and issues of communication emerged from the three main stages of production: 1) pre-production, 2) the tracker and top-line process and 3) mixing and finalizing. 


\section{Pre-production}

In the reflections, a number of students commented on the initial part of the tracker assessment. In particular, the formation of their groups and how students sought other students who had complimentary skillsets to their own as in this example:

Jordan - The Tracker process was the first time I'd delved in the area of programming and collaborating online with another songwriter/producer. For this process I was teamed up with Luke, who is a very talented producer with a great ear for tasteful songwriting and production. (Student creative synthesis assessment)

\section{The Tracker and Top-line Process}

The tracking stage in this assessment involved composing the rhythm or 'beat' and here 'students learn to record MIDI and dive into the vast libraries of sounds that most DAWs offer, or aurally peruse loop libraries for an ear-catching bass line, chord progression, or ambient pad' (Bell, 2019: 178). Because of the technical nature of the tracking process, a number of the students cited technical issues as a barrier to their collaboration. This was most acute when students were using different DAWs in order to complete this stage of the process as Anson describes below:

Anson - He and Levi both use Ableton, whereas I primarily use Reason. I am also fairly adept at Pro-tools and Reaper, but have absolutely no experience with Ableton. This immediately created a barrier in our possible workflow and as I had no means to access Ableton and no familiarity with it. This meant we could not use the method I was familiar with (Google Drive automatically updating the same files across everyone's computer as changes are made). (Student creative synthesis assessment)

The difference in DAW applications forced students to find solutions to overcome the issue of workflow as Anson explains:

Anson - It was a constant process of creating music in my own DAW then bouncing out stems for Alex to layer over the track. (Student creative synthesis assessment)

In addition to technical barriers during the tracking and top-lining process, the students also experienced difficulties in communicating, assessing and rejecting ideas through online means: 
Levi - Working in this manner felt slower and less progressive that what I am used to while working in a studio. Though I have engaged in a tracker, top-line writer collaboration experiences, the online collaboration provided a completely different experience. I found that working this way was much more exclusive while working on the song. Rather than working in a studio, "vibing" with each other's energy and having a working flow, progression felt slow working from audio files with little feedback. However, this also opened opportunity for personal working space, allowing a sense of creative freedom to work with your own ideas. It also leads a different form of songwriting. (Student creative synthesis assessment)

A number of the students commented that they found communicating online difficult and several of them emphasized that for particular tasks face-to-face communication was far more preferable:

Levi - Online collaboration seemed to be the overarching issue throughout this project, mainly due to a lack of communication. I personally had to find myself driving the project forward in person often, asking for progression to be sent and stems to be sent online. Unfortunately, due to unforeseen circumstances while moving houses, I was left without an Internet connection for up to two weeks and this hindered my progression being able to access files and upload files for my peers. (Student creative synthesis assessment)

Zak - The songwriting process was, for the most part, collaborative and in person as we found that communicating online made this process hard and drawn-out; we'd be able to easily hone in on a more succinct vision rather than aimlessly making up ideas separately, after which we'd finally be able to fully engage in the satellite model. This was also necessary as our availabilities clashed outside of Uni and as such, online communication was slower than desired. (Student creative synthesis assessment)

There were however some students who felt they thrived in the virtual environment because of the nature of their task (top-lining). For them, working remotely allowed them the time and space to try out ideas before presenting them to the rest of the group:

We worked well together as a team and quite productively. As a top-line writer it lessened the stress to write something in the moment with someone 
looking over my shoulder and made it easier to experiment. (Student response tracker survey)

\section{Mixing and Finalizing}

The final stages of mixing and finalizing the production involved the balancing and combining of the various elements of the track (top-line, beat) to create a cohesive musical production. Importantly: 'baked into this process of making creative decisions about the song's structure and elements is the continued use of studio technology' (Bell, 2019: 180) and in making these creative decisions, the students overwhelmingly chose to complete this stage face-to-face rather than online as Gabriele describes:

Gabriele - Finishing the song together was the best thing we could've done for the song since it allowed us to fully collaborate and easily and quickly bounce ideas off of each other. Especially production wise with the vocal effects used, and the smaller finishing details added to the song. It was a very instantaneous process that would've been impossible to do with the back and forth and time delays of communicating over messenger. The only way to somewhat replicate this would be using FaceTime or Skype: some kind of video chat. However, there's still a lot lost communicating through a screen, especially energy and vibe. (Student creative synthesis assessment)

\section{Collaboration and Assessment within the Tracker Process}

Responses from the students showed that collaboration allowed them to explore some of their usual customs and challenged them to evaluate them as shown in this example:

Dylan - James sent us a MIDI keys track for Michael to write a top-line part over and I began working on a percussive element to help reinforce the keys track. I used a horse trotting along a stone road as inspiration when creating the beat, but the midi keys had a number of ornate flourishes moving around, which made it difficult to use this style of percussion. This was a blessing in disguise because it made me reconsider the percussion, leading me to a simpler war-drum styled percussion. (Student creative synthesis assessment)

Collaboration also afforded students the opportunity to change their way of thinking in order to meet the expectations of the other students in the group: 
Jordan - I learnt more about the importance of communication and being open to any idea in this tracker process than I have in any other musical recording experience...Top-line writing has brought unique challenges such as unfamiliarity with the initial programmers' intentions and being under intense time pressure to finish the vocal component. I've certainly grown as a singer and musician/producer from the tracker process. (Student creative synthesis assessment)

In this way collaboration, both face-to-face and online, introduced new ways of working to the students, allowing them to learn from each other and underlined the importance of communication within the production process. The online nature of the assessment and the process in general also highlighted the importance of file management, version control and clear and concise communication to the students:

Dylan - Unfortunately for me I had downloaded the wrong keys track and had been programming drum/bass for an earlier version of the song, which made all of my programmed work incompatible with the more current version of the song. This comes down to poor communication, but it taught me how important consistent conversation is when you are working with people via correspondence. (Student creative synthesis assessment)

The use of online tools to enhance collaboration and the setting of rules of use of these tools were also underlined in this response:

Anson -This could have been done in 1/3rd the time if we had fully utilized file sharing and were working across the same DAW's and platforms while communicating in a single chat. In the real world this could potentially happen, so it's good to have this frame of reference coming out of the project; as I know what I can look forward to if I use this method to collaborate with people via distance again (which I will). I think the trick is setting out more defined ground rules and operating within a strict framework that's consistent across all platforms from the get-go. (Student creative synthesis assessment)

Students' overall perception was that this assessment item bridged their practice to the professional world. 
We live in a time period where collaborations are a fundamental aspect of initiating and furthering our career as musicians and producers. We won't always find suitable collaborators in a geographically ideal pace where we can easily meet up and write/record in person. It's vitally important that we're able to write with like-minded musicians who may live on the other side of the world. The tracker process is an excellent skill to learn in being able to achieve this kind of collaboration in the future. (Student response tracker survey).

Some students also suggested that the tracker process helped them to realize new collaborative possibilities:

Emily - I learned more about the importance of communication and being open to any idea in this tracker process than I have in any other musical recording experience. Now that I've had the experience of writing as a topline writer I would love to collaborate with ... other programmer/producers in other projects. (Student creative synthesis assessment)

Finally, the actual act of asking students to reflect on their processes allowed them to unpack what they had learned throughout:

Jordan - I learnt more-so from unpacking every aspect of the task in the journal. I reflected on the language we used, the effects of body language and knowledge of the collaborator. There are so many factors that contribute to the workflow, approach to and result of the tracker process. Every little bit needs to be considered. And I only knew exactly what I learnt when I unpacked it. (Student creative synthesis assessment)

\section{Issues, strategies and pedagogical considerations for embedding the tracker process within a popular music educational context.}

There are a number of issues that can arise during the tracker assessment. Firstly, as shown in the responses above, some students who lost access to the Internet were unable to collaborate effectively and the other group members were unaware of where the production process had progressed to. Secondly, the mixture of DAW platforms can create issues of compatibility and students can find it difficult to integrate their use of DAW software as they are confronted with the realities of importing bounced audio from other DAWs. Importantly though, the assessment 
item's primary focus is to engage the students with the realities of the recording industry and so these issues are a part of the profession-based learning experience. Students are challenged within this module to find solutions such as seeking a better Internet connection or learning how to work across various DAW software applications. As a last resort, students can always come into the university to facilitate their remote engagement and music production activities in one of the university's studios. This is all informed by the module's 'challenge to students' that is presented in lecture 1: find a solution to any roadblock to the music-making process rather than making excuses as this is what is expected of entrepreneurs in the industry. This way, issues that need to be solved actually become central to the learning process, a process identified in the pedagogical literature as problem-based learning (PBL) (see e.g. Barell 2007; Savin-Baden and Wilkie 2006).

There are a number of pedagogical considerations for embedding the tracker process within PME. Firstly, educators need to ensure that students undertaking the assessment have suitable prior knowledge and skills in songwriting, music programming and music production. This could be through strategic curriculum design allowing students to learn these skills and gain this knowledge within the program for example. In addition, the student cohort needs to consist of musicians who are able to assume the various roles involved with the tracker process, which are the tracker and the top-liner. However, this form of assessment also promotes the engagement of a third student who can operate as a mediator/producer and, if this role is not required, then the producer role can be subsumed by either of the first two students, or as a collaboration of the two.

Accessibility is a second and important consideration. Students all need access to a DAW with music production software similar to Pro Tools, Logic or Ableton Live to facilitate their remote music-making. They also require access to a location that has a suitable Internet connection for larger file transfers, as much of the collaboration of this module is online. Although this promotes students' learning in a music production context that isn't limited to in-situ collaboration, access to the Internet with a suitable connection speed is vital for optimum communication and collaboration. Accessibility to appropriate equipment is also necessary. It is intended that students engage with this module from their home environment or any external studio environments but for the vocal-recording part of the process it is vital that students have access to a suitable microphone, preamplifier and compressor. For the mixing stage also students require suitable plugins (UAD, Waves, Slate) and so, if equipment isn't able to be loaned for these tasks, students should be encouraged to use the university studios and equipment to maintain a professional sonic aesthetic. 
Additionally, there is no stipulation as to who sings the song, students are encouraged to source the most appropriate vocalist form their cohort as a session vocalist, which encourages students to network, socialize and act as intermediaries and entrepreneurs to complete the work. If session vocalists aren't available in the cohort then students should be encouraged to look outside the University within the local musical community.

In addressing these considerations there are numerous strategies that can be implemented in embedding the tracker process into a PME context 1) providing and facilitating feedback and 2) creating a focus on the process rather than the product. Firstly, the overarching pedagogical mechanism that is necessary as a part of this module is peer reflection and so dedicated feedback and reflection tutorials at weeks 4 and 6 (see Table 1) are strategically placed to help kick start any struggling groups. Week 4 is designed to facilitate strategies for both groups who are collaborating well and groups who are yet to assimilate their ideas effectively. Week 6 is a dedicated 'top-line' tutorial but also has an opportunity for groups to source suitable singers for the songs they are writing/producing. These feedback sessions can encourage a collaborative learning environment that bridges to professional practice and helps to promote quality student engagement. The activity often confronts students with the reality of 'working with people'; some students are not $100 \%$ accountable to 'university work' and this can lead to conflict within collaborations. During tutorials students are coached on the psychology of collaboration, how to work through difficult situations and how to learn from issues that occur in order to develop an understanding of the social realities of music production. After three iterations of this module students have emphasized that the assessment placed them into the realities of modern music making and that the task 'felt' real. This highlights the value in pedagogy that stays 'in sync' with an evolving music industry (Lebler and Weston, 2015) and bridges formal education with profession-based scenarios.

Secondly, feedback sessions allow the educator the opportunity to assess the progress of each tracker group and target any potential groups that may be struggling and help students to learn the skill of giving and receiving feedback in a professional way. Allowing students to engage and learn about different communication modes within a professional context teaches students how to talk to people about their ideas, their work and, more importantly, how to receive positive and often negative reflections of their own work.

Finally, embedding the tracker process in PME can be made more potent by emphasising to students that 'process' is much more important than the musical 
result; this is not to say that the quality of the musical product is not important; rather, the process is the primary concern within the learning process. If the experience fuels thoughts of professional music production agency for the student, if it encourages students to make music in new ways, communicate with new people, all within a popular music making landscape then the assessment has accomplished its primary goal. The creative synthesis (assessment) then gives the student the vehicle to unpack the process and express their thoughts which allows them to learn from the experience and continue to develop as popular musicians.

\section{Conclusion}

In this study, we have introduced the changing role of the producer and specifically the 'tracker' producer. The tracker production process is a modern form of music production agency where top-line songwriters work with music programmers called 'trackers' primarily within the confines of the DAW. In this case, production, songwriting and performance often happen concurrently and collaboration involves the synthesis of ideas, musical negotiations and expertise in using digital and online technologies. The tracker process is currently a very popular mode of music production that is used across many popular music genres. Formal education however has been slow to create frameworks that relate to professional practice; the case study presented here was an attempt to address this particular need focusing on students' perceptions and experiences of learning the tracker process.

This study documents one particular participant group (a popular music cohort from Australia), it is therefore important to be cautious of generalisation for contrasting student demographics from across the globe. However, we would suggest that this research offers data and inspiration that may be useful in expanded study. Through this article we have presented numerous examples of the value of a pedagogical approach that places students within a primarily online music production scenario, where collaboration is principally through the Internet. The responses from the students showed how this type of pedagogical design can broaden the students' experiences of music production agency, develop knowledge and skills outside of their initial expertise and provide an opportunity to help them unpack their experiences within a practice-based context. This encourages an active role in the learning process on the student's part, whilst at the same time, providing a pedagogical bridge between the student experience and the actuality of the profession. It encourages the development of the student's skills and most importantly prepares students for industry engagement. 
The results we have presented here have introduced some useful issues, strategies and challenges in providing 'profession-based' popular music production learning activities, particularly where much of the communication and collaboration is undertaken online. In so doing, the study design we have provided here can be used in other Higher Education institutions that deliver popular music education.

However, additional research in similar settings could help to increase our understanding of how music production pedagogy should be designed and delivered in order to provide a more contemporary educational experience that resonates with the professional world of music production. 


\section{References}

Anthony, Brendan (2015), 'Creative conceptualisation: Nurturing creative practice through the popular music pedagogy of live recording production', International Association for the Study of Popular Music, 5(1), pp. 139-156.

Anthony, Brendan (2018), 'Mixing as a performance: Educating tertiary students in the art of playing audio equipment whilst mixing popular music', Journal of Music Technology and Education, 11(1), pp. 103-122.

Anthony, Brendan \& Lefford, Nyssim (2019), 'The producer's vision: A study into the multi-faceted conceptions of the popular music recording aesthetic'. Journal article currently under submission for publication with the International Association for the Study of Popular Music.

Auvinen, Tuomas (2016), 'A New Breed of Home Studio Producer: Agency and Cultural Space in Contemporary Home Studio Music Production', Etnomusikologian vuosikirja, (28), Suomen Etnomusikologinen Seura. http://etnomusikologia.journal.fi/article/view/60227.

Auvinen, Tuomas (2017), 'A New Breed of Home Studio Producer?: Agency and the Idea 'Tracker' in Contemporary Home Studio Music Production', Journal on the Art of Record Production, (11), https://www.arpjournal.com/asarpwp/a-new-breed-ofhome-studio-producer-agency-and-the-idea-tracker-in-contemporary-home-studio$\underline{\text { music-production/ }}$

Barell, John (2007), Problem-based learning: an inquiry approach, $2^{\text {nd }} \mathrm{ed}$., Thousand Oaks, CA: Corwin Press

Bell, Adam (2019), 'Of Trackers and Top-Liners: Learning producing and producing learning', In Z. Moir, B. Powell, \& G. D. Smith (Eds.), The Bloomsbury Handbook of Popular Music Education: Perspectives and Practices, New York, NY:

Bloomsbury.

Bennett, Joe (2011), 'Collaborative songwriting: The ontology of negotiated creativity in popular music studio practice', Journal on the Art of Record Production (5), http://arpjournal.com/collaborative-songwriting-\%E2\%80\%93-the-ontology-ofnegotiated-creativity-in-popular-music-studio-practice/

Bennett, Joe (2015), 'Creativities in popular songwriting curricula: Teaching or learning?', In P. Burnard \& E. Haddon (Eds.), Activating diverse musical creativities: Teaching and learning in higher music education, pp. 37-57, London: Bloomsbury.

Bennett, Joe (2017), 'Towards a framework for creativity in popular music degrees', In G. D. Smith, Z. Moir, M. Brennan, S. Ramabaran, \& P. Kirkman (Eds.), The Routledge research companion to popular music education pp. 285-297. New York, NY: Routledge.

Bennett, Joe (2018), 'Songwriting, Digital Audio Workstations, and the Internet'. In N. Donan (Ed.), The Oxford Handbook of Creative Process in Music, pp. 1-30. New York, N.Y: Oxford.

Bryman, Alan (2008), Social research methods, 3rd ed., Oxford, NY: Oxford University Press.

Burgess, Richard (2008), 'Producer compensation: Challenges and options in the new music business'. Journal on the Art of Record Production, (3). 
http://arpjournal.com/producer-compensation-challenges-and-options-in-the-newmusic-business/

Burgess, Richard (2014), The history of music production, New York, NY: Oxford University Press.

Cohen, Louis, Manion, Lawrence and Morrison, Keith (2000), Research methods in Education, ( $5^{\text {th }}$ edition), London: Routledge.

Cremata, Radio (2017), 'Facilitation in popular music education', Journal of Popular Music Education, 1(1), pp. 63-82. doi:10.1386/jpme.1.1.63_1

Creswell, John (2005), Educational research: Planning, conducting, and evaluating quantitative and qualitative research. Upper Saddle River, NJ: Pearson Prentice Hall.

Csikszentmihalyi, Mihaly (1997), Creativity: The psychology of discovery and invention, New York, NY: Harper Perrennial.

Davis, Robert, Parker, Steven and Thompson, Paul (2014), 'Preparing the music technology toolbox: Addressing the education-industry dilemma', Journal of Music, Technology \& Education, 7(3), pp. 313-323.

Draper, Paul (2007), 'Students doing the driving: how undergraduates use ICT to enhance reflective practice, peer review and collaborative learning, Proceedings of the NACTMUS National Conference, Brisbane (29) pp. 1-10.

Folkestad, Goran (2006), 'Formal and informal learning situations or practices vs formal and informal ways of learning', British journal of music education, 23(2), pp. $135-145$.

Graham, Robin (1979), Practical synthesis for electronic music, (1). Japan: Roland.

Green, Lucy (2002), How popular musicians learn: A way ahead for music education. Surrey: Ashgate.

Green, Lucy (2006), 'Popular music education in and for itself, and for 'other' music: Current research in the classroom', International journal of music education, 24(2), pp. 101-118.

Hepworth-Sawyer, Russ. and Golding, Craig (2010), What is music production?: A producer's guide: The role, the people, the process. Burlington, MA: Taylor \& Francis.

Hiltunen, Riikka (2016), 'Luovia valintoja rajoitetussa tilassa', Popkappaleen tekeminen ryhmätyönä Biisilinna 2015 -leirillä’. Etnomusikologian vuosikirja, (28). Suomen Etnomusikologinen Seura.

https://etnomusikologia.journal.fi/article/view/60231.

Howlett, Mike (2007), 'Fixing the volatile studio: Studio vocal performance techniques', Paper presented at the 3rd Art of Record Production Conference, Queensland University of Technology, Brisbane. http://eprints.qut.edu.au/33275/

Howlett, Mike (2009), The record producer as nexus: Creative inspiration, technology and the recording industry. (PhD), University Of Glamorgan.

Hugill, Andrew (2012), The digital musician. New York, NY: Routledge. 
King, Andrew (2016), 'Studio pedagogy: Perspectives from record producers', In A. King \& E. Himonides (Eds.), Music, technology, and education: Critical perspectives, pp. 45-66, New York, NY: Routledge.

Kolb, David (1984). Experiential learning: Experience as the source of learning and development. Englewood Cliffs, NJ: Prentice-Hall.

Koszolko, Martin (2017), 'The giver: A case study of the impact of remote music collaboration software on music production process', Internation Association for the Study of Popular Music, 7(2), pp. 32-40.

Lave, Jean and Wenger, Etienne (1991), Situated learning: Legitimate peripheral participation. Cambridge, MA: Cambridge University Press.

Lebler, D. (2007), 'Student-as-master? Reflections on a learning innovation in popular music pedagogy', International journal of music education, 25(3), pp. 205221, doi:10.1177/0255761407083575

Lebler, Don (2008), 'Popular music pedagogy: Peer learning in practice', Music Education Research, 10(2), pp. 193-213. doi:10.1080/14613800802079056

Lebler, Don and Weston, Donna (2015), 'Staying in sync: Keeping popular music pedagogy relevant to an evolving music industry, International Association for the Study of Popular Music, 5(1), pp. 124-138.

Macedo, Fredrico (2013), 'Teaching creative music technology in higher education: A phenomenological approach', Journal of Music, Technology and Education, 6(23), pp. 207-219, doi:10.1386/jmte.6.2.207_1

McIntyre, Philip (2007), 'Learning to be songwriters: Creativity, the systems model and domain acquisition', Paper presented at the 2005 IASPM Australia/New Zealand Conference

Moorefield, Virgil (2005), The Producer as Composer: Shaping the Sounds of Popular Music. Cambridge: MIT Press.

Moylan, William (2002), The art of recording: Understanding and crafting the mix. Boston, MA: Focal Press.

Salavuo, Miikka (2006), 'Open and informal online communities as forums of collaborative musical activities and learning', British Journal of Music Education, 23(3), pp. 253--271.

Savin-Baden, Maggi and Wilkie, Kay (2006), Problem-based learning online. Maidenhead, NY: Open University Press.

Sawyer, Keith (2003), Creativity and development, Oxford: Oxford University Press.

Seabrook, John (2015), The song machine: Inside the hit factory, New York, NY: Norton.

Senior, Mike (2011), Mixing secrets for the small studio, Abingdon: Taylor \& Francis.

Shulman, Lee (2005), 'Signature Pedagogies in the Professions', Daedalus, 134(3), pp. 52-59, doi:10.1162/0011526054622015 
Small, Christopher (1998), Musicking: the Meaning of Performing and Listening. Middletown: Wesleyan University Press.

Strange, Allen (1972), Electronic music: systems, techniques, and controls. Dubuque, IA: W. C. Brown Co.

Théberge, Paul (2000), 'The project ahead: Some thoughts on developing a popular music curriculum', Canadian University Music Review, 21(1), pp. 28-39, doi:10.7202/1014476ar

Théberge, Paul (2012), 'The end of the world as we know it: The changing role of the studio in the age of the internet', In S. Frith \& S. Zagorski-Thomas (Eds.), The art of record production: An introductory reader for a new academic field, pp. 7790, Burlington, VT: Ashgate.

Thompson, Paul (2012), An empirical study into the learning practices and enculturation of DJs, turntablists, hip hop and dance music producers. Journal of Music, Technology and Education, 5(1), pp. 43-58.

Thompson, Paul. (2019). Creativity in the Recording Studio: Alternative Takes. Basingstoke: Palgrave Macmillan.

Thompson, Paul and Harding, Philip (2018), 'Service Models in Popular Music Production Education', Paper presented at the 13th Art of Record Production conference, University of Huddersfield, UK.

Voss, Bett (2016), 'Information on demand in the recording studio: Building the case for teaching music technology with an interactive agenda', Australian Journal of Music Education, 50(2), pp. 24-38.

Voss, Brett (2018), 'The Design Principles of On-Demand Learning: A DesignBased Research Study of Educative Provisioning in Popular Music Production', Doctoral thesis, Griffith University, Australia.

Waldron, Janice (2016), 'An Alternative Model of Music Learning and "Last Night's Fun": Participatory Music Making In/As Participatory Culture in Irish Traditional Music', Action, Criticism, and Theory for Music Education, 15(3), pp. 86-112.

Waldron, Janice, Mantie, Roger, Partti, Heidi and Tobias, Evan (2018), 'A brave new world: theory to practice in participatory culture and music learning and teaching', Music Education Research, 20(3), pp. 289-304.

Wong, Hei Ting (2017), 'Popular Music education in Hong Kong: A case study of the Baron School of Music', In G. D. Smith, Z. Moir, M. Brennan, S. Ramabaran, \& P. Kirkman (Eds.), The Routledge research companion to popular music education pp. 100-113, New York, NY: Routledge.

Zak, A (2001), The poetics of rock: Cutting tracks, making records, Los Angeles, CA: University of California Press. 


\section{Appendix A Tracker assessment survey}

\section{Tracker process survey}

A survey of higher education students who engaged in the tracker process.

*Required

What is your age *

$17-21$

$22-30$

$30-40$

over 40

Which of the following terms describe your current popular music role? Please check as many boxes as necessary *

\section{Song writer}

Producer

Programmer (sequencer)

Musician/singer

Which of the following roles did you fulfill during your engagement with the tracker process. Please check as many boxes as necessary. *

$\square$ Top liner

$\square$ Tracker (programmer)

$\square$ Producer

Musician/singer 
During the tracker process how often did you engage with songwriting? *

All of the time

Most of the time

$50 \%$ of the time

Some of the time

Never

During the tracker process how often did you engage with programming? *

All of the time

Most of the time

$50 \%$ of the time

Some of the time

Never

During the tracker process how often did you engage with production? *

\section{All of the time}

Most of the time

$50 \%$ of the time

Some of the time

Never 
During the tracker process how often did you engage with musicality and performance. *

All of the time

Most of the time

$50 \%$ of the time

Some of the time

Never

What kinds of technologies do you need to be able to engage in the tracker process? How does this effect the process and outcome? *

Your answer

Please describe the social interaction you experienced during the tracker experience? (face to face and remote/online). *

Your answer

How did online or remote collaboration affect your musical productivity? *

Your answer

To what extent do you feel the tracker process results in a different type of musical output as compared to traditional approaches of composing with an instrument? *

Your answer 